\title{
Rigid swelling of sublingual caruncle area due to the salivary gland duct obstruction by a sialolith*
}

Fred Bernardes Filho ${ }^{1,2}$

Andreia Oliveira Alves ${ }^{4}$

David Rubem Azulay ${ }^{1,2}$
Gustavo Martins ${ }^{3}$

José Ronaldo Vieira da Costa ${ }^{5}$

Luna Azulay-Abulafia ${ }^{1,6}$

Abstract: Sialolithiasis is the presence of calculus within the ductal system of a salivary gland. Among the diagnostic methods are inspection, palpation, checking the amount of saliva secreted and the identification of a sialolith. The authors present the case of a 37-year-old female patient with edema of the submandibular area and a bulging sublingual caruncle due to a calculus that obstructed the salivary gland ostium.

Keywords: Oral medicine; Salivary duct calculi; Salivary gland calculi

\section{INTRODUCTION}

Oral Pathology, Maxillofacial and Stomatology are specialties that have as objective the prevention, diagnosis, prognosis and treatment of mouth diseases, their adjacent structures and the face, as well as buccal manifestations of systemic illnesses. ${ }^{1}$ Sialolithiasis is the presence of a calculus, known as sialolith, in the ductal system of a salivary gland. This my happen at any age but is more common in young people and middle-aged adults, affecting approximately $1.2 \%$ of the population. It is related to the submandibular gland in $83 \%$, to the parotid gland in $10 \%$ and sublingual in $7 \%$ of cases. The main function of salivary glands is production and excretion of saliva, which plays a lubricant, digestive and antibacterial role that may be compromised in this process. $^{2}$

The main symptoms of the patient with salivary gland calculi are decrease of saliva secretion, pain and dysphagia. The signs are increased volume of the glands involved, with or without presence of local inflammatory and/or infectious process. ${ }^{2}$ During massage of the gland ("milking"), decreased salivary flow or purulent exudate may be observed. The severity of symptoms depends on the degree of obstruction, as well as the calculus size and location. ${ }^{3,4}$

Received on 30.09.2013.

Approved by the Advisory Board and accepted for publication on 21.10.2013.

Work carried out at the Instituto de Dermatologia Professor Rubem David Azulay, Santa Casa da Misericórdia do Rio de Janeiro (IDPRDA-SCMRJ) - Rio de Janeiro (RJ), Brazil.

Financial Support: None

Conflict of Interests: None.

Instituto de Dermatologia Professor Rubem David Azulay, Santa Casa da Misericórdia do Rio de Janeiro (IDPRDA-SCMRJ) - Rio de Janeiro (RJ), Brazil. Pontifícia Universidade Católica do Rio de Janeiro (PUC RJ) - Rio de Janeiro (RJ), Brazil.

Private Clinic - Ituiutaba (MG), Brazil.

Centro Universitário Barão de Mauá - Ribeirão Preto (SP) - Brazil.

Universidade Federal de Alfenas (UNIFAL) - Alfenas (MG), Brazil.

Universidade do Estado do Rio de Janeiro (UERJ) - Rio de Janeiro (RJ), Brazil.

(C)2014 by Anais Brasileiros de Dermatologia 
Clinical history and presentation are fundamental in the sialolithiasis diagnosis. Exams like radiography, computed tomography, magnetic resonance, ultrasonography, sialoendoscopy and sialography may assist the doctor in the diagnosis and best treatment. ${ }^{2,3}$ Mucocele is a clinical differential diagnosis and its treatment consists of electrocoagulation, surgical exeresis or marsupialization of the affected gland, to prevent relapses. ${ }^{1}$ The differential diagnosis should also be done with obstructive sialoadenitis, epidemic parotiditis and salivary gland tumors. ${ }^{5,6}$

The authors present the case of a female patient with increased volume of the submandibular region and tumefaction of the area proximal to the lower lingual frenulum, resulting from a sialolith that obstructed the left submandibular salivary gland ostium.

\section{CASE REPORT}

A female patient, 37 years old, came to the dermatology outpatient clinic one hour after a meal, with increased volume of the left submandibular region associated with the onset of a lesion described as a painless aphtha on the base of the tongue one day before. She mentioned a sensation of having parotiditis, although she had had mumps in childhood. Upon examination, tumefaction was observed in the proximal region of the lower lingual frenulum with presence of a yellowish spot, hard on palpation, at the center of the lesion (Figure 1). Due to the topography and hardened consistency, it was hypothesized that a sialolith might be obstructing the left submandibular salivary gland ostium. A massage of this salivary gland ("milking"), clamping and calculus extraction were carried (Figure 2). After the duct of the salivary gland was unclogged, a great quantity of saliva was drained and symptoms relieved (Figure 3).

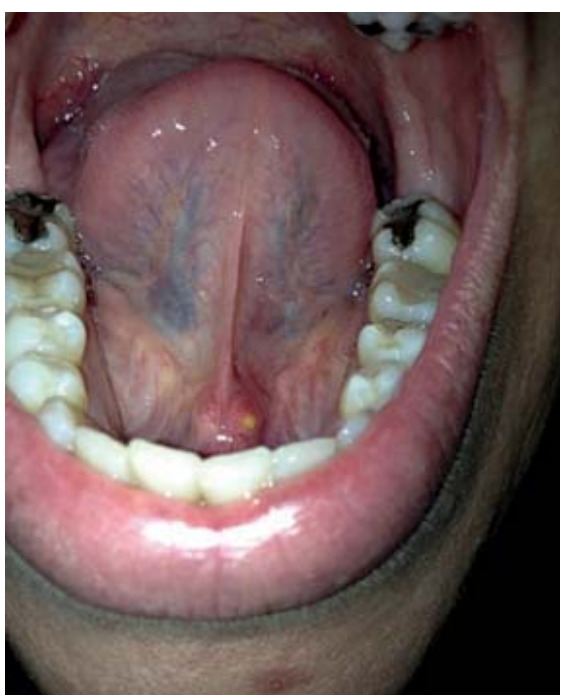

Figure 1:

Tumefaction of region proximal to lower lingual frenulum with a sialolith obstructing the left submandibular salivary gland ostium (sublingual caruncle)

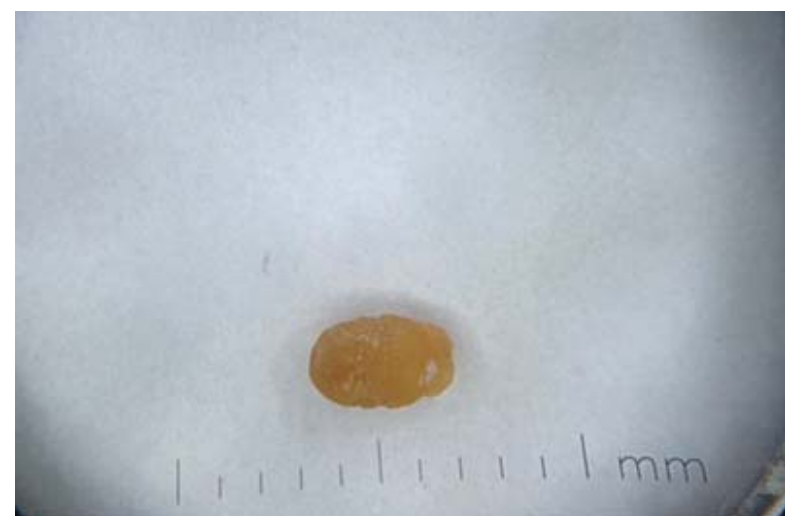

FigURE 2: Yellow - colored sialolith measuring $4 \times 2 \mathrm{~mm}$

\section{DISCUSSION}

The examination of lips, oral cavity and mucosa is part of the dermatological examination. ${ }^{7}$ There are alterations typical of the mucosae, oral manifestations of dermatoses and mucosal manifestations of systemic disease. The histological and anatomical characteristics of the oral mucosa impart to the lesions aspects oftentimes diverse from when the skin is affected and the dermatologist should be familiarized with their presentation. ${ }^{1,7}$

Sialoliths are calcified structures that develop in the interior of the ductal or acini system of salivary glands, blocking or limiting saliva flow. This pathology corresponds to around $30 \%$ of salivary alterations and is also the most common cause of obstruction of these glands. ${ }^{1,8}$ The most frequently affected location is the ductal system of the submandibular gland, with 80 to $90 \%$ of cases. The long, tortuous and ascending pathway of the submandibular duct as well as the thick mucosal secretion are described as accountable

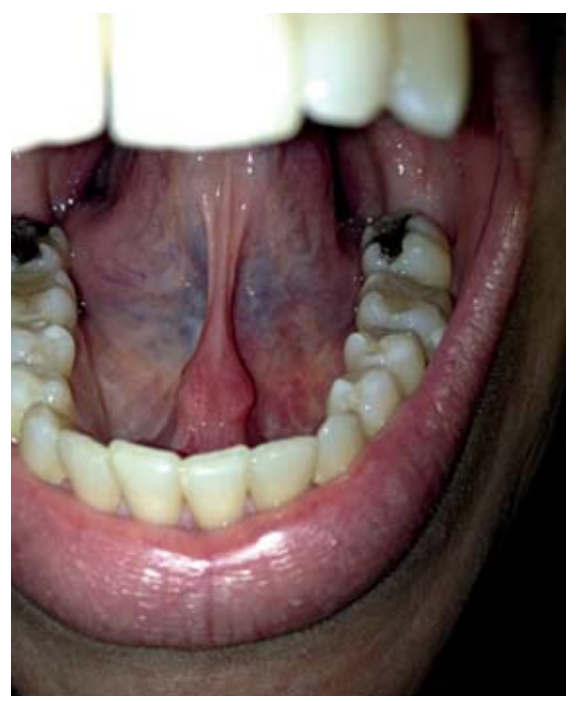

FIGURE 3:

Decrease of volume of lower sublingual frenulum base after the submandibular salivary gland ostium was cleared 
factors for greater tendency to calculi formation in these glands, which may also be aggravated by tobacco use. ${ }^{1,5}$

In general, smaller sialoliths located in the gland duct deserve a conservative approach, by means of salivary stimulation, duct manipulation and catheterism. ${ }^{9}$ Sialolithiasis recurrence seems to be related to the individual susceptibility to these concrescences formation. ${ }^{2}$

The authors emphasize the importance of attention to this diagnosis by the dermatologist, since the oral cavity examination should be a routine in specialty clinical care. The obstruction of the salivary gland caused by a sialolith may result in increased volume of the parotid, sublingual or submandibular region, in accordance with the topography of the affected gland. In the studied case, although it was not photographed, there was increased volume of the left submandibular region, a fact that, associated with the presence of a calculus obstructing the left submandibular salivary gland ostium, guided the correct diagnosis. The inclusion of sialolithiasis among the differential diagnosis for tumefactions of sublingual and submandibular regions should be remembered in everyday activities of outpatient clinics, since the clinical diagnosis may not be so evident as in this case, making it necessary to request imaging exam for diagnostic clarification.

\section{REFERENCES}

1. Neville BW, Damm DD, Allen CM et al. Patologia Oral e Maxilofacial. 3 ed. Philadelphia: Elsevier; 2009. 972 p.

2. Harrison JD. Causes, natural history, and incidence of salivary stones and obstructions. Otolaryngol Clin North Am. 2009;42:927-47.

3. Thomas BL, Brown JE, McGurk M. Salivary gland disease. Front Oral Biol. 2010;14:129-46.

4. Armstrong MA, Turturro MA. Salivary gland emergencies. Emerg Med Clin North Am. 2013;31:481-99.

5. Gabrielli MAC, Gabrielli MFR, Paleari AG, Neto NC, Silva LMC, Dantas JFC. Treatment of sialolithiasis in submandibular glands: report of two cases. Robrac. 2008; 17:110-6.

6. Uluc ME, Vidinli BD, Erdogan N, Gelal F. Giant cystic dilatation that includes multiple sialolithiasis of submandibular gland. Otolaryngol Head Neck Surg. 2006;134:533-4.

7. Sampaio SAP, Rivitti EA. Afecções dos lábios e da mucosa oral. In: Sampaio SAP, Rivitti EA, editores. Dermatologia. São Paulo: Artes Médicas; 2008. p. 1339-57.

8. Grases F, Santiago C, Simonet BM, Costa-Bauzá A. Sialolithiasis: mechanism of calculi formation and etiologic factors. Clin Chim Acta. 2003;334:131-6.

9. Koch M, Zenk J, Iro H. Algorithms for treatment of salivary gland obstructions. Otolaryngol Clin North Am. 2009;42:1173-92.

\author{
MAILING ADDRESS: \\ Fred Bernardes Filho \\ Rua Marquês de Caxias, $n^{\circ}$ 9, Sobrado, Centro. \\ 24030-050. Niterói - RJ \\ Brasil. \\ E-mail: f9filho@gmail.com
}

How to cite this article: Bernardes Filho F, Martins G, Alves AO, Costa JRV, Azulay DR, Azulay-Abulafia L. Rigid swelling of sublingual caruncle area due to the salivary gland duct obstruction by a sialolith. An Bras Dermatol. 2014;89(6):977-9. 